\title{
INFLUENCE OF MINING AND AGRICULTURAL ACTIVITIES ON THE QUALITY OF GROUNDWATER FROM SOME RURAL AREAS OF SOUTH-EASTERN NIGERIA
}

\author{
ITUMOH E.J. ${ }^{1}$ \\ AGHAMELU O.P. ${ }^{2}$ \\ IZUAGIE T. ${ }^{3}$
}

\author{
${ }^{1}$ Department of Industrial Chemistry, Ebonyi State University Abakaliki \\ Ebonyi State, Nigeria \\ ${ }^{2}$ Department of Physics/Geology/Geophysics \\ Federal University Ndufu-Alike, Ikwo, Ebonyi State, Nigeria \\ ${ }^{3}$ Department of Chemistry, Sokoto State University \\ Sokoto State, Nigeria
}

Received: $26 / 12 / 2014$

Accepted: $17 / 03 / 2015$

Available online: 15/05/2015

*to whom all correspondence should be addressed: e-mail: ray.chukwuemekajude@yahoo.com

\section{ABSTRACT}

This study examined the trends in anthropogenic chemical contaminants in groundwater samples in rural areas of Ebonyi State, South-eastern Nigeria. Groundwater samples were collected from Ezza North (a quarry mining area) and Ezza South (an agricultural/commercial area) and were analysed using standard techniques. The target compounds evaluated were $\mathrm{As}(\mathrm{V})$, phosphate, nitrate, sulfate, chloride and other physicochemical parameters. Pearson's correlation and factor analyses were used to distinguish the statistical relationship between the various analytes and possible contamination sources in the study areas, respectively. The results obtained showed that the $\mathrm{pH}$, temperature, total hardness, electrical conductivity, phosphate, nitrate, chloride and sulfate were within the permissible limits of Water Quality Standards (WQS). Also, $67 \%$ of the samples had turbidity and alkalinity values above the WQS, while $25 \%$ contained $\mathrm{As}(\mathrm{V})$ slightly above the WQS. The qualities of the groundwater samples were found to be influenced mainly by the geochemistry of the soil while commercial and agricultural activities were found to have slight effect on the water quality. This study finally advocates adequate monitoring of $\mathrm{As}(\mathrm{V})$, and other potential toxic contaminants in groundwater in the areas.

Keywords: groundwater, arsenic, chemical contaminants, mining area, factor analysis

\section{Introduction}

The Report of the British Geological Survey (Natural Environment Research Council) on Nigeria in 2005 recommended studies on groundwater quality with emphasis on the impacts of arsenic, fluoride and sanitation. This, according to the report, was because most of the rural people in Nigeria depended on groundwater supply, with over half not having access to safe and reliable water supply, which is vital for better health and poverty reduction (MacDonald et al., 2005). In order to meet the Millennium Development Goals (MDGs) target of 2015, which is to reduce by half the number of people without access to safe reliable water supplies, it is imperative to monitor water sources for the levels of their chemical contaminants (Gómez et al., 2012). However, many studies on the chemical contaminants of groundwater in Nigeria are focused mainly on total trace metal contents and other well-known contaminants, with little or no studies done on the levels of the speciated forms of metals (e.g. arsenic). Though, arsenic is present in the environment in a number of different inorganic and organic forms, due to its participation in complex biological and chemical processes (Villa-Lojo et al., 2002), As(III/V) are the predominant in water. Under oxidizing conditions, $\mathrm{As}(\mathrm{V})$ predominates and is found in the common $\mathrm{pH}$ 
range of most natural ground- and surface waters as the oxyanions $\mathrm{H}_{2} \mathrm{AsO}_{4}{ }^{-}(\mathrm{pH}<6.8)$ and $\mathrm{HAsO}_{4}{ }^{2-}$ $(\mathrm{pH}>6.8)$. In water with reducing conditions, $\mathrm{As}(\mathrm{III})$ is the predominant oxidation state while the neutral species $\mathrm{H}_{3} \mathrm{AsO}_{3}$ predominates in water with $\mathrm{pH}<9.2$ (Bundschuh et al., 2012).

Thus, this study is aimed at examining the trends in chemical contaminants of groundwater sources of rural communities that are affected by mining and agricultural activities. As(V) was the major targeted chemical contaminant monitored. This was because of its inherent toxicity. It was also a least studied chemical contaminant in groundwater in the study area. However, other contaminants were studied to enable a wider discussion of the chemical water quality of the samples.

\section{Experimental Section}

\subsection{Background of the sampled area}

The study area is, geologically, underlain by the Asu River Group (Reyment, 1965), as shown in Figure 1. The Asu River Group sediments are predominantly shales, and with localized occurrences of sandstone, siltstone and limestone intercalations. This group was generally believed to have started depositing in the mid-Albian period and was deposited within the lower (or southern) Benue Trough, South-eastern Nigeria. It has an average thickness of about $5000 \mathrm{~m}$, and was dark grey in colour but was wathered to brownish clayey shale or laterites in the greater part of the formation. The group is deeply folded, faulted and fractured by the series of tectonic activities which has acted on the rocks (Ezeh and Anike, 2009). This has given the shales the ability to house groundwater at economic quantity in some areas. The major part of the area is underlain by aquiclude; except in locations or zones where secondary aquiferous conditions were made possible by syn- and post depositional circumstances. The syn-depositional circumstance is the occurrence of lenses of sandstone or siltstone beds, while the post depositional circumstances include weathering, fracturing or shearing, and volcanic intrusions. The zones are recharged mostly in the peak of rainy season and by surface waters in the area.

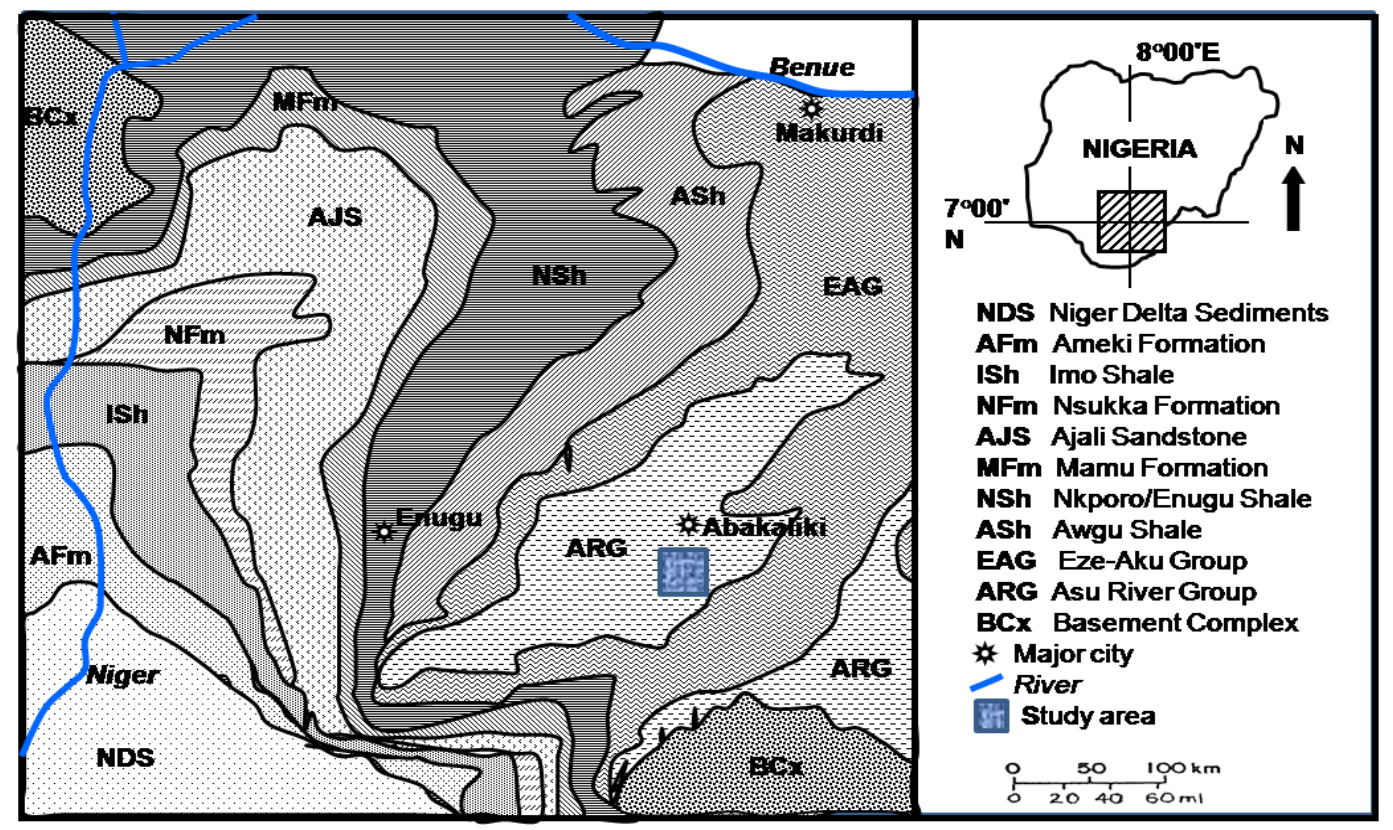

Figure 1. Geological map of South-eastern Nigeria showing the study area

The study area is bounded by latitude $6^{0} 09^{1}$ to $6^{0} 14^{1} \mathrm{~N}$, longitude $8^{0} 05^{1} \mathrm{E}$ to $8^{0} 10^{1} \mathrm{E}$ (Figure 2). The sampled points in Ezza South are around Onueke which is about $23 \mathrm{~km}$ south of Abakaliki metropolis, while the points in Ezza North are about $4-6 \mathrm{~km}$ from Abakaliki metropolis. The area falls within the rainforest climatic region of South-Eastern Nigeria where the rainy season spans from April to October and the dry season from October to April. The average annual rainfall of the study area is about $1500 \mathrm{~mm}$ 
with actual surface temperature (seasonal temperature) of between $24-36^{\circ} \mathrm{C}$ during dry season and about $18{ }^{\circ} \mathrm{C}$ during the rainy season. The study area is of high leached red soils of tropical forest areas with the vegetation dominated by grasses, shrubs and trees e.g. palm trees, coconut, mango, and orange trees (Omaka et al., 2014). The major occupation of the people living in the area is farming (Ezza South) and mining activities (Ezza North). Pb-Zn mining and quarrying for construction work are secondary occupations to the people (Nnabo et al. 2011).
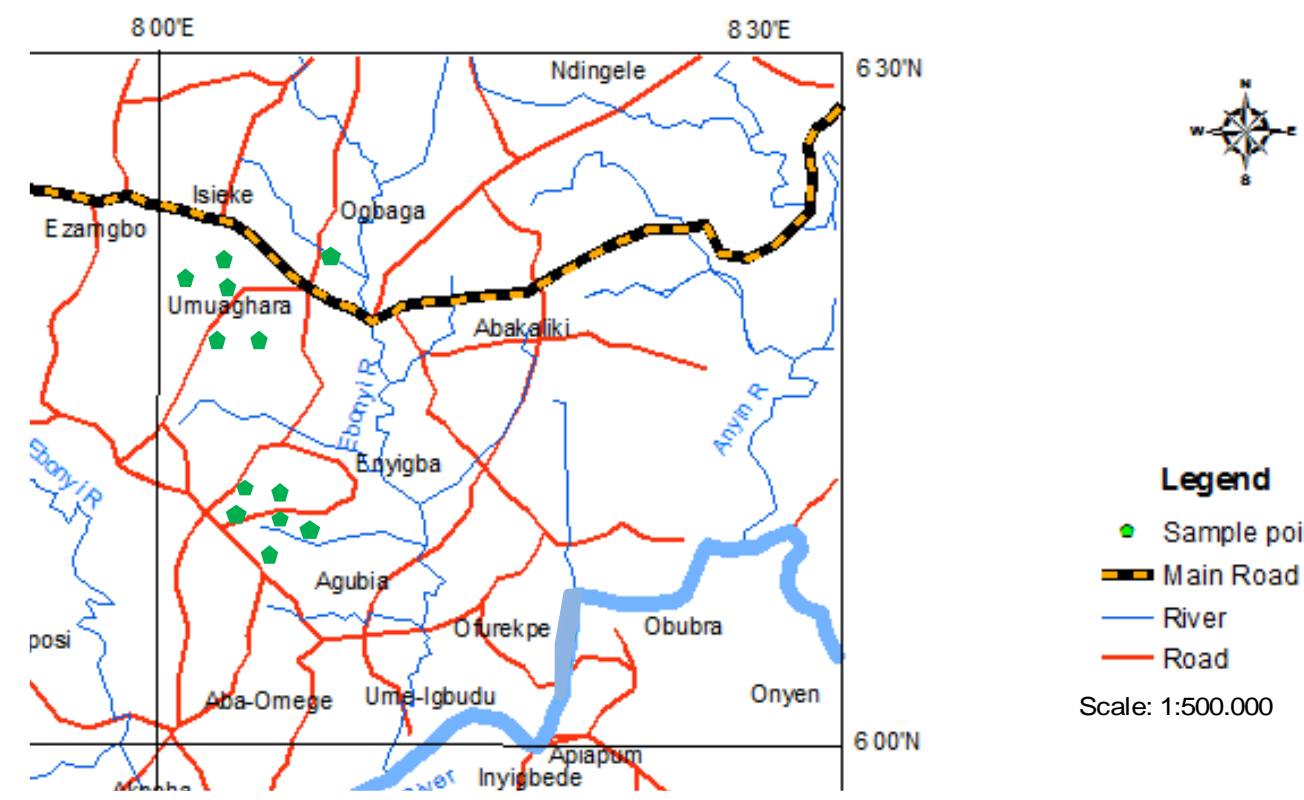

- Sample point

Main Road

- River

Road

Scale: 1:500.000

Figure 2. Map of the study area showing the sample points

\subsection{Analytical methods}

\subsubsection{Apparatus and equipment}

All Spectrophotometric determinations were carried out using Genesys 10S UV - vis Spectrophotometer (Thermo Fisher Scientific Inc., Madison WI, USA). Chemical reagents were weighed using a precision (0.0001 g) balance, (Mettler -Toledo International Inc., Columbus, OH, USA). The accuracy of the balance was checked with standard mass references. Other analytical probes were also used - Hach Sension $3 \mathrm{pH}$ meter (Hach Company, Loveland, Colo. USA). The pH meter was standardized each time before use; LCD portable digital multi-stem thermometer with external probe (Model - ST -9269); A pocket-size conductivity meter (Hanna Instruments, Italy); Hach Sension + DO 6 (Crison Instruments, S.A. Barcelona, Spain).

\subsubsection{Sampling and sampling procedure}

The water samples were collected according to standard procedures (Mendham et al. 2004). All items for collecting and storing samples and reagents were first washed with distilled deionised water (DDW), soaked overnight in $10 \%(\mathrm{v} / \mathrm{v})$ nitric acid and then rinsed exhaustively with DDW. The washed items were dried and stored in zip locked polyethylene bags (Pistón et al. 2012). Twelve groundwater samples (six samples per area) were collected twice per month between March and July 2013. Water samples were filtered (except for samples for the determination of analytes other than $A s(V)$ ) and collected into these precleaned wide mouthed containers (ca. 1 litre) with cap. The containers were completely filled with water and capped to prevent spillage. Exposure of the samples to air was minimized during the filtration to reduce the possibility of oxidation (Bednar et al. 2004). Tests on each sample were carried out upon return to the laboratory, between one to six hours of collection. Whereupon not possible to meet the period of analysis, there was a re-sampling. $\mathrm{pH}$, temperature, dissolved oxygen; conductivity and turbidity were carried out in-situ at the sampling sites using probes. 


\subsubsection{Sample description}

The description of the samples and the names of the sample locations are presented in Table 1 . The names of the locations are as verified by the locals who assisted in getting through to the sampling location.

Table 1. The description of the samples according each local government area

\begin{tabular}{lll}
\hline Sample & Location & Description \\
\hline EN 1 & Ezza North & Hand-pumped borehole at Alozie village \\
EN 2 & & Hand-pumped borehole at Ogbaga village \\
EN 3 & Hand-pumped borehole at Onunwafor village \\
EN 4 & Hand-pumped borehole at Ogueru village \\
EN 5 & Hand-dug well water at Ogueru village \\
EN 6 & Hand-dug well water at Alozie village \\
& & \\
\hline ES 1 & Ezza South & Hand-dug well water at Eke Imoha Onueke \\
ES 2 & & Hand-pumped borehole at Eke Imoha Onueke \\
ES 3 & Hand-dug well water at Nsokkara Achara Ukwu \\
ES 4 & Hand-pumped borehole at Nsokkara Achara Ukwu \\
ES 5 & Hand-dug well water at Ezama Amaolenya village \\
ES 6 & Hand-pumped borehole at Ezama Amaolenya village \\
\hline
\end{tabular}

\subsubsection{Determination of $A s(V)$}

Several methods have been optimised for the determination of total and speciated forms of arsenic in water (Pistón et al. 2012; Villa-Lojo et al. 2002; Bednara et al. 2004). This study adopted the method of Nyamah and Torgbor (1986). This is because the technique is relatively simple, affordable, easily available and had proven to be sensitive. The technique is based on the quantitative reaction of arsenate with iodide, releasing an equivalent amount of iodine in the presence of sulphuric acid. The liberated iodine is then extracted immediately with carbon tetrachloride and the absorbance measured spectrophotometrically at $515 \mathrm{~nm}$ (Nyamah and Torgbor, 1986).

\subsubsection{Determination of Physicochemical parameters (total hardness and alkalinity)}

The total hardness (TH) and total alkalinity (TA) were determined according to the guidelines of American Public Health Association (APHA), American Water Works Association (AWWA) and Water Environment Federation (WEF), (2012).

\subsubsection{Determination of Phosphate}

The phosphate content of the samples were analysed as described elsewhere (Omaka, 2007).

\subsubsection{Determination of Nitrate}

Nitrate content of the samples were determined as described in Jenkins and Medsken (1964).

\subsubsection{Determination of Sulfate}

The method for the determination of sulfate was based on the reaction of sulfate with barium chloride as described in APHA, AWWA and WEF, (2012).

\subsubsection{Determination of Chloride}

The chloride content of the samples was determined as described in APHA, AWWA and WEF (2012).

\section{Statistical analysis}

The data generated in this study were computed using Microsoft Excel Spreadsheet 2007 (Data analysis ToolPak). The descriptive statistics and correlation analysis were computed using Microsoft Excel 
Spreadsheet 2007. The factor analysis model was performed using Paleontological Statistics (PAST) software Package for Education and Data Analysis, version 2.17c (2013).

\section{Results and Discussion}

The results of the chemical contaminants analysed in this study are presented in Table 2 . The results were categorized according to each local government area for easy understanding. The mean values $(n=6)$ were compared with Water Quality Standards (WQS) set by World Health Organisation (WHO, 2011), Standard Organisation of Nigeria (SON, 2007) and National Agency for Food, Drug Administration and Control (NAFDAC, 2007) in Nigeria. The skewness and kurtosis of each contaminant is also presented. The Skewness characterizes the degree of asymmetry of a distribution around its mean. Positive skewness indicates a distribution with an asymmetric tail extending toward more positive values. Negative skewness indicates a distribution with an asymmetric tail extending toward more negative values. The Kurtosis characterizes the relative peakedness or flatness of a distribution compared with the normal distribution. Positive kurtosis indicates a relatively peaked distribution. Negative kurtosis indicates a relatively flat distribution. The mean value $(n=10)$ of each contaminant for each sample is represented graphically in Figures 3 and 4. Generally from the results, within period of this study, no great seasonal variations of parameters from the sampled groundwater were observed. Rather, a temporal trend of the parameters was observed.

\subsection{Physicochemical parameters}

The $\mathrm{pH}$ of the samples was alkaline, and was within the upper limits of the prescribed standards except for the sample, ES 5, which was slightly above the limit with 0.1 unit $(\mathrm{pH} 8.6)$. However, the results of the $\mathrm{pH}$ showed that the water samples were not influenced by treatment breakdowns (for the boreholes) or other accidental spills (for the hand-dug wells) which affect the $\mathrm{pH}$ of groundwater (Sundaram et al. 2009). The temperature range of the water samples could be described as ambient since they are slightly above the normal room temperature $\left(25^{\circ} \mathrm{C}\right)$. The ambient temperature of the samples will contribute little impact on the levels of inorganic constituents and chemical contaminants. The electrical conductivities of ES 1, ES 6 and ES 5 were very high $\left(800,843\right.$ and $943 \mu \mathrm{cm}^{-1}$ respectively, $\left.n=10\right)$ which are consistent with the high total dissolved solids (TDS) recorded (398, 403 and $599 \mathrm{mg} \mathrm{l}^{-1}$ respectively). According to WHO (2011) the palatability of water with a total dissolved solids (TDS) level of less than about 600 $\mathrm{mg}^{-1}$ is generally considered to be good and drinking-water becomes significantly and increasingly unpalatable at TDS levels greater than $1000 \mathrm{mg} \mathrm{l}^{-1}$. In that regards, the levels of TDS recorded in the water samples are not considered hazardous to the villagers. Samples EN 1, EN 3 and EN 6 gave high mean levels $(n=10)$ of alkalinity $\left(217.7 \mathrm{mg} \mathrm{l}^{-1}, 200.7 \mathrm{mg} \mathrm{l}^{-1}\right.$ and $237.7 \mathrm{mg} \mathrm{l}^{-1}$ respectively). This could have resulted from the dissolved bicarbonates (especially magnesium bicarbonates) abundant in the areas. Water hardness of the samples were found to be relatively high especially for sample EN $3\left(21.6 \mathrm{mg} \mathrm{l}^{-1} \mathrm{CaCO}_{3}\right)$, ES $3(10.4$ $\left.\mathrm{mg} \mathrm{l}^{-1} \mathrm{CaCO}_{3}\right)$, ES 6 (6.5 mg l-1 $\left.\mathrm{CaCO}_{3}\right)$ and EN 4 (6.2 $\left.\mathrm{mg} \mathrm{l}^{-1} \mathrm{CaCO}_{3}\right)$. Though there is no notable health implications of hardness of water (WHO, 2011), the levels of water hardness recorded were far below the prescribed standard. Generally, samples from the hand-dug wells were found to have high levels of turbidity than samples from boreholes. This is expected since they are poorly constructed (hand-dug), open and non-cemented. This resulted in high incidences of particle and dust deposition and seepages from nearby potholes or drainages. This may be the possible explanation to high turbidity levels recorded in EN 5 (17 NTU) as there were lots of mini-potholes around the well occasioned by rainfall, flooding and erosions. Comparing all the samples on the basis of the levels of physicochemical parameters recorded, ES 6 seemed to be highly polluted, with almost high levels of all the parameters. This could be possibly linked to the effects agricultural and commercial activities close to the site. 
Table 2. The chemical contaminants analysed in water samples collected from the two local government areas $(n=6)$

\begin{tabular}{|c|c|c|c|c|c|c|c|c|c|c|}
\hline \multirow{2}{*}{ Location } & \multirow{2}{*}{ Analyte } & \multirow{2}{*}{ Unit } & \multicolumn{3}{|c|}{ Concentration } & \multirow[t]{2}{*}{ Skewness } & \multirow[t]{2}{*}{ Kurtosis } & \multicolumn{3}{|c|}{ WQS } \\
\hline & & & Range & Mean & S. variance & & & WHO & NAFDAC & SON \\
\hline \multirow{13}{*}{ Ezza South } & $\mathrm{pH}$ & - & $7.30-8.60$ & 7.9 & 0.227 & 0.343 & -0.218 & $6.5-8.5$ & - & $6.5-8.5$ \\
\hline & Temperature & ${ }^{\circ} \mathrm{C}$ & $26.20-29.80$ & 28.1 & 2.746 & -0.781 & -1.620 & - & - & Ambient \\
\hline & Elect. Conductivity & $\mu S \mathrm{~cm}^{-1}$ & $125.0-943.0$ & 641.7 & 105675.867 & -1.045 & -0.655 & - & - & 1000.0 \\
\hline & Dissolved Oxygen & $\mathrm{mg} \mathrm{l}^{-1}$ & $9.40-10.20$ & 9.9 & 0.094 & -0.692 & -0.632 & - & - & - \\
\hline & T. Dissolved Solid & $\mathrm{mg} \mathrm{l}^{-1}$ & $286.0-599.0$ & 423.5 & 10584.300 & 0.773 & 1.930 & 600 & - & - \\
\hline & Alkalinity & $\mathrm{mg} \mathrm{l}^{-1}$ & $6.70-237.70$ & 97.0 & 7184.267 & 0.695 & 0.719 & - & 100.0 & - \\
\hline & T. Hardness & $\begin{array}{l}\mathrm{mg} \mathrm{l}^{-1} \\
\mathrm{CaCO}_{3}\end{array}$ & $1.80-6.50$ & 4.6 & 11.652 & 1.101 & 0.430 & - & - & 150 \\
\hline & Turbidity & NTU & $3.00-14.00$ & 7.7 & 14.267 & 0.755 & 1.100 & 5 & - & 5 \\
\hline & Phosphate & $\mathrm{mg} \mathrm{l}^{-1}$ & $0.130-0.180$ & 0.162 & 0.000 & -0.839 & -0.059 & - & - & - \\
\hline & Chloride & $\mathrm{mg} \mathrm{l}^{-1}$ & $105.8-182.6$ & 120.623 & 997.603 & 2.041 & 4.503 & 250.0 & - & - \\
\hline & Nitrate & $\mathrm{mg} \mathrm{l}^{-1}$ & $0.59-0.85$ & 0.718 & 0.009 & -0.222 & -0.874 & $5-50$ & - & - \\
\hline & Sulfate & $\mathrm{mg} \mathrm{l}^{-1}$ & $25.09-37.17$ & 31.182 & 23.753 & 0.122 & -1.815 & - & - & 100 \\
\hline & Arsenic(V) & $\mathrm{mg} \mathrm{l}^{-1}$ & $0.006-0.011$ & 0.008 & 0.000 & 0.962 & -1.834 & 0.010 & - & 0.010 \\
\hline \multirow{13}{*}{ Ezza North } & $\mathrm{pH}$ & - & $7.60-8.10$ & 7.9 & 0.035 & -1.281 & 1.853 & $6.5-8.5$ & - & $6.5-8.5$ \\
\hline & Temperature & ${ }^{\circ} \mathrm{C}$ & $28.10-29.30$ & 28.7 & 0.234 & 0.296 & -1.707 & - & - & Ambient \\
\hline & Elect. Conductivity & $\mu S \mathrm{~cm}^{-1}$ & $35.0-584.0$ & 272.0 & 272.0 & 0.420 & -1.909 & - & - & 1000.0 \\
\hline & Dissolved Oxygen & $\mathrm{mg} \mathrm{l}^{-1}$ & $9.55-10.20$ & 9.7 & 0.134 & -0.543 & 1.276 & - & - & - \\
\hline & T. Dissolved Solid & $\mathrm{mg} \mathrm{l}^{-1}$ & $27.0-315.0$ & 173.7 & 16055.86 & -0.178 & -2.469 & 600 & - & - \\
\hline & Alkalinity & $\mathrm{mg} \mathrm{l}^{-1}$ & $14.7-217.7$ & 120.0 & 7176.667 & -0.176 & -1.963 & - & 100.0 & - \\
\hline & T. Hardness & $\begin{array}{l}\mathrm{mg} \mathrm{l}^{-1} \\
\mathrm{CaCO}_{3}\end{array}$ & $1.2-21.60$ & 6.2 & 60.387 & 2.186 & 4.915 & - & - & 150 \\
\hline & Turbidity & NTU & $4.00-17.00$ & 8.5 & 23.500 & 1.264 & 1.176 & 5 & - & 5 \\
\hline & Phosphate & $\mathrm{mg} \mathrm{l}^{-1}$ & $0.14-0.42$ & 0.253 & 0.016 & 0.800 & -1.911 & & & \\
\hline & Chloride & $\mathrm{mg} \mathrm{l}^{-1}$ & $63.16-177.9$ & 116.665 & 2367.889 & 0.360 & -1.808 & 250.0 & - & - \\
\hline & Nitrate & $\mathrm{mg} \mathrm{l}^{-1}$ & $0.64-0.89$ & 0.792 & 0.009 & -0.692 & -0.430 & $5-50$ & - & - \\
\hline & Sulfate & $\mathrm{mg} \mathrm{l}^{-1}$ & $19.21-42.94$ & 36.990 & 79.109 & -2.229 & 5.157 & - & - & 100 \\
\hline & Arsenic(V) & $\mathrm{mg} \mathrm{l}^{-1}$ & $0.002-0.011$ & 0.005 & 0.000 & 1.360 & 2.149 & 0.010 & - & 0.010 \\
\hline
\end{tabular}

WQS = water quality standards according to World Health Organisation (WHO, 2011), Standard Organisation of Nigeria (SON, 2007) and National Agency for Food, Drug Administration and Control (NAFDAC, 2007), Nigeria as reported in Duruibe et al. (2007) 


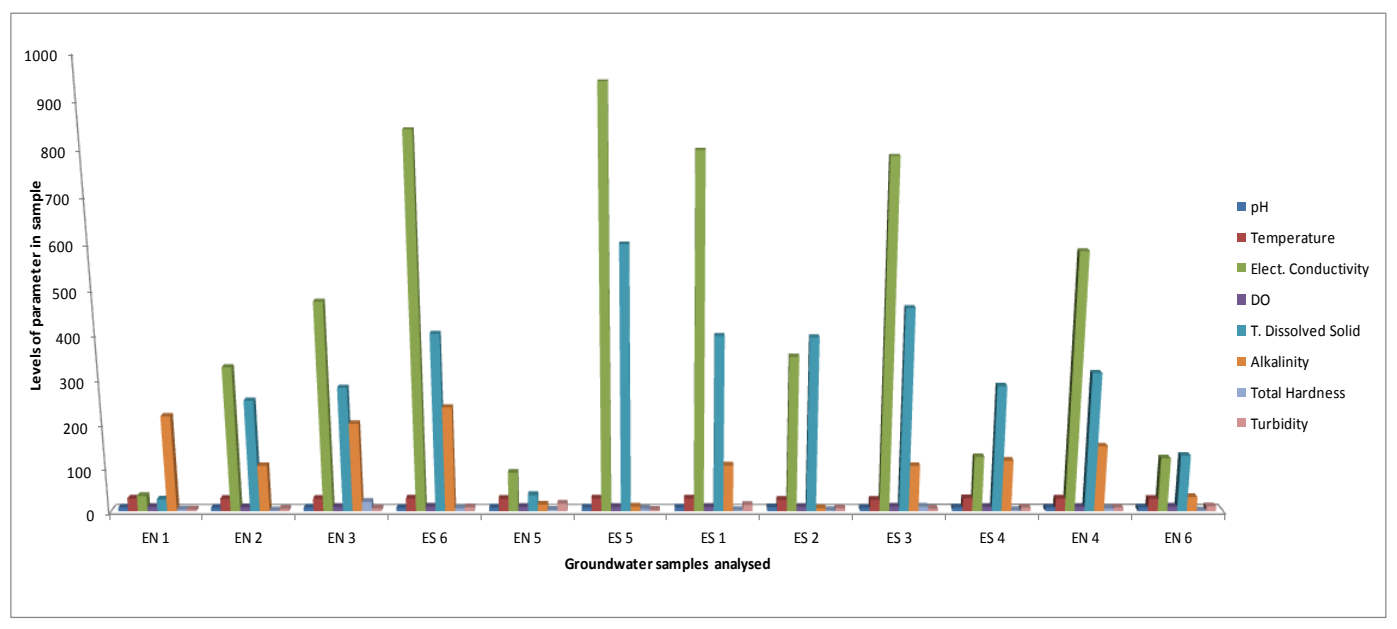

Figure 3. The mean values $(n=10)$ of physicochemical contaminants in the groundwater samples in the two areas

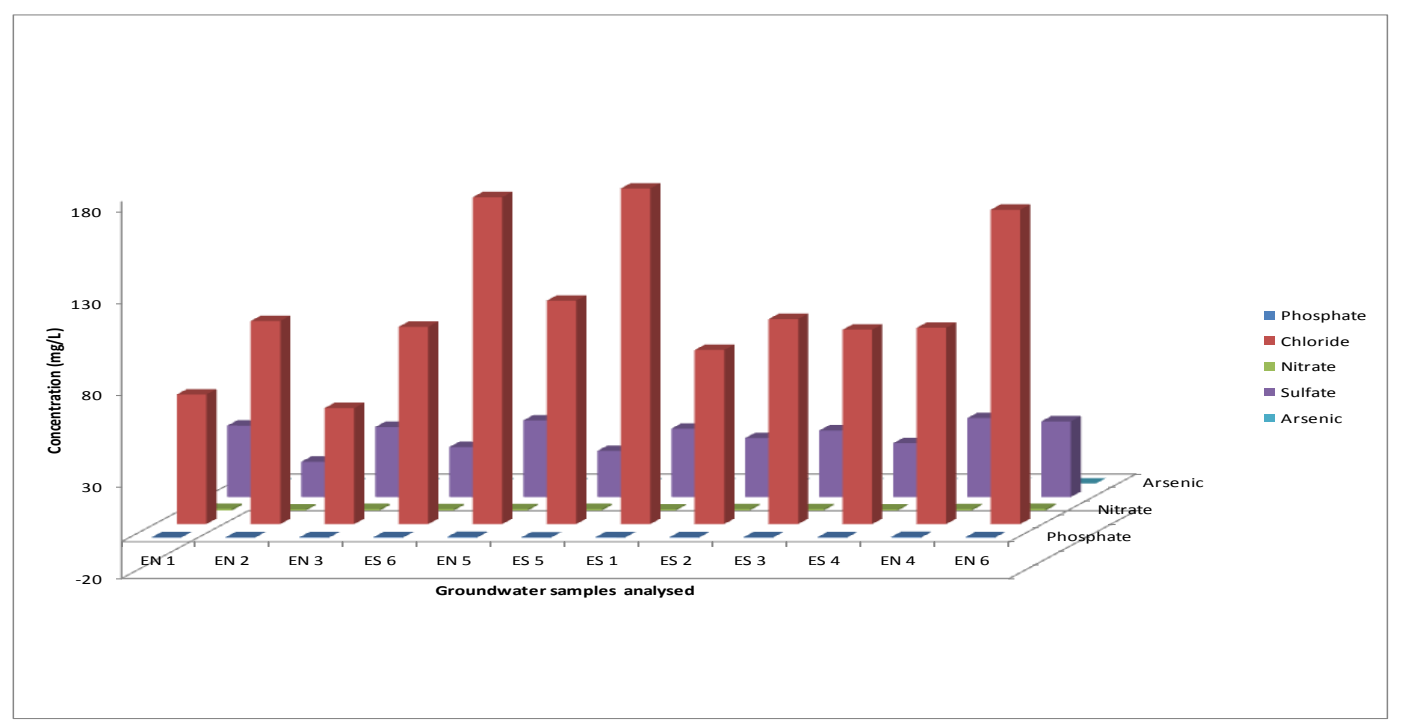

Figure 4. The mean values $(n=10)$ of targeted and other chemical contaminants in the groundwater samples in the two areas

\subsection{Phosphate and Nitrate}

The results obtained for phosphate and nitrate were within the WQS prescribed limits. The study of the levels of phosphate and nitrate concentrations in the samples was important for various reasons. Phosphate and nitrate enrichment of waters contributes to ecological impacts (Prior and Jones, 2002) and are notable characteristic pollutants for eutrophication of natural waters (Zanin et al,. 1998; Withers and Lord, 2002; Halliwell et al,. 1996). Also, high concentration of nitrate in drinking water sources can be fatal to humans and animals (Monteiro et al., 2003; Zatar et al., 1999), while elevated concentration of phosphorus results in fouling of natural water and production of toxic cyanobacteria (Omaka, 2007). Finally, the study areas are rural communities where domestic agricultural practices are predominant (although Ezza North is noted for quarry mining). It is expected that agricultural activities, such as the use of phosphate and urea fertilizers, could contribute significantly to the concentrations of the nutrients in the samples analyzed. High levels of nutrient contamination of water sources are best managed by protecting the source water from contamination. This is because they are difficult to remove, although disinfection will oxidize nitrite (the more toxic form) to nitrate (WHO, 2011). The relatively high mean levels $(n=10)$ of phosphate in EN 4 and EN 5 ( 0.42 and $0.41 \mathrm{mg} \mathrm{l}^{-1}$ respectively) is likely from agricultural 
activities which are also carried in the area. This could also be true of EN 1 and EN $6\left(0.88 \mathrm{mg} \mathrm{l}^{-1}\right.$ and 0.89 $\mathrm{mg} \mathrm{I}^{-1}$ respectively). Generally, with high levels of phosphate and nitrate in ES 4, the sample could be considered as the most polluted even though the levels are within the limits.

\subsection{Sulfate and chloride}

From the graphical representation in Figure 4, the results of sulfate and chloride are highly noticeable because they show high mean concentrations especially the chloride. Compared with the WQS, they are below the prescribed limits. However, the presence of sulfate in drinking-water can cause noticeable taste, and very high levels might cause a laxative effect in unaccustomed consumers. It is true that WHO has no health-based guideline value derived for sulfate, the organisation believes that taste impairment varies with the nature of the associated cation and that taste thresholds have been found to range from $250 \mathrm{mg} \mathrm{l}^{-1}$ for sodium sulfate to $1000 \mathrm{mg} \mathrm{l}^{-1}$ for calcium sulfate (WHO, 2011). The levels of chloride found in the water samples analysed in this study could have originated from natural sources (geochemistry).

Table 3. The values of correlation matrix for the analytes in Ezza North

\begin{tabular}{|c|c|c|c|c|c|c|c|c|c|c|c|c|c|}
\hline Analyte & $\mathrm{pH}$ & Temp. & EC. & DO & TDS & Alk. & TH & Turb. & $\mathrm{PO}_{4}{ }^{3-}$ & $\mathrm{Cl}^{-}$ & $\mathrm{NO}_{3}{ }^{-}$ & $\mathrm{SO}_{4}{ }^{2-}$ & $\mathrm{As}(\mathrm{V})$ \\
\hline pH & 1.00 & & & & & & & & & & & & \\
\hline Temp. & 0.01 & 1.00 & & & & & & & & & & & \\
\hline EC. & -0.40 & -0.15 & 1.00 & & & & & & & & & & \\
\hline DO & 0.04 & -0.37 & 0.14 & 1.00 & & & & & & & & & \\
\hline TDS & -0.21 & -0.27 & 0.88 & 0.05 & 1.00 & & & & & & & & \\
\hline Alk. & -0.51 & 0.37 & 0.10 & 0.04 & -0.13 & 1.00 & & & & & & & \\
\hline TH & -0.24 & -0.09 & 0.30 & 0.20 & 0.18 & 0.47 & 1.00 & & & & & & \\
\hline Turb. & 0.31 & 0.17 & -0.21 & 0.38 & -0.38 & -0.26 & -0.29 & 1.00 & & & & & \\
\hline $\mathrm{PO}_{4}{ }^{3-}$ & 0.39 & 0.24 & 0.20 & 0.25 & 0.01 & -0.49 & -0.20 & 0.74 & 1.00 & & & & \\
\hline $\mathrm{Cl}^{-}$ & 0.43 & -0.50 & -0.41 & 0.41 & -0.38 & -0.98 & -0.61 & 0.87 & 0.55 & 1.00 & & & \\
\hline $\mathrm{NO}_{3}^{-}$ & 0.64 & 0.44 & -0.27 & 0.72 & -0.31 & 0.29 & 0.20 & -0.10 & -0.24 & -0.15 & 1.00 & & \\
\hline $\mathrm{SO}_{4}^{2-}$ & 0.87 & 0.58 & -0.08 & 0.80 & -0.28 & -0.04 & 0.16 & 0.46 & 0.51 & 0.19 & 0.69 & 1.00 & \\
\hline $\operatorname{As}(\mathrm{V})$ & 0.32 & 0.47 & -0.72 & 0.19 & -0.80 & 0.22 & -0.31 & -0.05 & -0.18 & -0.08 & 0.64 & 0.43 & 1.00 \\
\hline
\end{tabular}

Values considered significant are in bold $(\geq 0.5)$. Negative significant values show inverse correlation.

Temp. = Temperature, EC. = Electrical Conductivity, DO = Dissolved Oxygen, TDS $=$ Total Dissolved Solid, Alk = Alkalinity, $\mathrm{TH}=$ Total Hardness, Turb. = Turbidity

\section{4. $A s(V)$}

Arsenic is found widely in Earth's crust in oxidation states of $-3,0,+3$ and +5 , often as sulfides or metal arsenides or arsenates. Irrespective of the specie, the concentration in natural waters is usually less than $1-2 \mathrm{~g} \mathrm{I}^{-1}$, but could be significantly elevated in the presence of sulfide mineral deposits and sedimentary deposits derived from volcanic rocks (WHO, 2011). The results of the 12 groundwater samples of this study showed varied concentrations, which are believed to be strongly related to natural geochemistry, rather than anthropogenesis. This is because of the relatively low concentrations observed in the samples. The concentrations of arsenic(V) in the samples from Ezza South area gave mean values $(n=10)$ of approximately $0.006 \mathrm{mg} \mathrm{l}^{-1}$, except for ES 1 and ES 4 which had mean values of 0.010 and $0.011 \mathrm{mg} \mathrm{l}^{-1}$ respectively. These results strongly suggest similar sources of enrichments or contamination. ES 1 is a hand-dug well water sample and this could have contributed to the mean value. The samples from Ezza North had relatively lower mean concentrations $\left(<0.007 \mathrm{mg} \mathrm{l}^{-1}\right)$, except for EN $1\left(0.011 \mathrm{mg} \mathrm{l}^{-1}\right)$. The values do not reflect effects of contamination from quarry mining activities in the area contrary to expectations. Generally, environmental factors such as redox potentials or presence of Fe-Mn oxyhydroxides, particularly Mn oxides, could have affected the levels (enrichment) of arsenic(V) in the water samples. This is because dissolved heavy metals adsorb strongly to Mn oxides due to its large specific surface area, and $\mathrm{Mn}$ is widespread in the environment (Heal, 2001). These factors were not investigated in this study. However, there is possibility of bio-accumulation of $\mathrm{As}(\mathrm{V})$ in human and other animal consumers of the water samples since $\mathrm{As}(\mathrm{V})$ has not been demonstrated to be highly essential to humans. Acute toxicity of 
arsenic compounds in humans is predominantly a function of their rate of removal from the body (SteinerAsiedu, et al. 2010).

Table 4. The values of correlation matrix for the analytes in Ezza South

\begin{tabular}{|c|c|c|c|c|c|c|c|c|c|c|c|c|c|}
\hline Analyte & $\mathrm{pH}$ & Temp. & EC. & DO & TDS & Alk. & TH & Turb. & $\mathrm{PO}_{4}{ }^{3-}$ & $\mathrm{Cl}^{-}$ & $\mathrm{NO}_{3}{ }^{-}$ & $\mathrm{SO}_{4}{ }^{2-}$ & $A s(V)$ \\
\hline pH & 1.00 & & & & & & & & & & & & \\
\hline Temp. & -0.03 & 1.00 & & & & & & & & & & & \\
\hline EC. & -0.46 & -0.05 & 1.00 & & & & & & & & & & \\
\hline DO & -0.32 & -0.55 & 0.08 & 1.00 & & & & & & & & & \\
\hline TDS & -0.15 & -0.19 & 0.77 & -0.34 & 1.00 & & & & & & & & \\
\hline Alk. & -0.68 & 0.32 & 0.15 & 0.56 & -0.42 & 1.00 & & & & & & & \\
\hline TH & -0.84 & -0.47 & 0.57 & 0.45 & 0.42 & 0.33 & 1.00 & & & & & & \\
\hline Turb. & 0.19 & 0.35 & -0.08 & 0.30 & -0.58 & 0.43 & -0.43 & 1.00 & & & & & \\
\hline $\mathrm{PO}_{4}{ }^{3-}$ & 0.27 & -0.10 & -0.34 & 0.69 & -0.69 & 0.44 & -0.32 & 0.66 & 1.00 & & & & \\
\hline $\mathrm{Cl}^{-}$ & 0.08 & 0.35 & 0.41 & -0.15 & 0.08 & 0.04 & -0.20 & 0.68 & -0.03 & 1.00 & & & \\
\hline $\mathrm{NO}_{3}^{-}$ & -0.19 & -0.36 & 0.62 & -0.06 & 0.86 & -0.26 & 0.49 & -0.73 & -0.42 & -0.36 & 1.00 & & \\
\hline $\mathrm{SO}_{4}{ }^{2-}$ & 0.07 & -0.47 & -0.03 & 0.46 & -0.29 & -0.03 & 0.11 & 0.50 & 0.28 & 0.49 & -0.48 & 1.00 & \\
\hline As(V) & 0.19 & 0.61 & -0.39 & -0.24 & -0.62 & 0.18 & -0.56 & 0.73 & 0.17 & 0.60 & -0.92 & 0.35 & 1.00 \\
\hline
\end{tabular}

Values considered significant are in bold $(\geq 0.5)$. Negative significant values show inverse correlation

Temp. $=$ Temperature, EC. = Electrical Conductivity, DO = Dissolved Oxygen, TDS $=$ Total Dissolved Solid, Alk = Alkalinity, $\mathrm{TH}=$ Total Hardness, Turb. = Turbidity

\subsection{Correlation analysis}

Correlation analysis is used to calculate correlation coefficient between two measurement variables when measurements on each variable are observed for each of $n$ subjects. Correlation between all the analytes was carried out by using Pearson's correlation matrix. Tables 3 and 4 show the correlation coefficients between the analytes in the study areas. Based on the Pearson's correlation, there is significant and positive correlation (for values $\geq 0.5$ ) between the two variables marked in bold. This implies that there is relationship between the analytes in each case.

Table 5. Factor Analysis numbers (Varimax rotation) of various analytes in Ezza North

\begin{tabular}{|c|c|c|c|c|}
\hline Analyte & Factor 1 & Factor 2 & Factor 3 & Factor 4 \\
\hline $\mathrm{pH}$ & 0.80772 & 0.55429 & -0.17774 & 0.082885 \\
\hline Temp. & 0.79765 & 0.57227 & -0.16722 & 0.076742 \\
\hline EC. & 0.42266 & 0.88063 & -0.1792 & -0.11524 \\
\hline DO & 0.80916 & 0.55109 & -0.18236 & 0.086713 \\
\hline TDS & 0.45715 & 0.87732 & -0.13662 & 0.048147 \\
\hline Alk. & 0.33196 & 0.87313 & -0.35642 & -0.0017481 \\
\hline TH & 0.2234 & 0.62586 & -0.74698 & -0.013251 \\
\hline Turb. & 0.95973 & 0.20451 & -0.16748 & -0.069747 \\
\hline $\mathrm{PO}_{4}{ }^{3-}$ & 0.86241 & 0.42647 & -0.073672 & -0.26044 \\
\hline $\mathrm{Cl}^{-}$ & 0.94675 & 0.30671 & -0.035111 & 0.088891 \\
\hline $\mathrm{NO}_{3}^{-}$ & 0.80337 & 0.54554 & -0.21481 & 0.09574 \\
\hline $\mathrm{SO}_{4}{ }^{2-}$ & 0.83549 & 0.47991 & -0.2468 & -0.049982 \\
\hline$A s(V)$ & 0.93962 & 0.28254 & -0.16654 & 0.0044065 \\
\hline
\end{tabular}

Values of factors that had strong positive loading on the analyte are in bold $(\geq 0.6)$.

Temp. $=$ Temperature, EC. $=$ Electrical Conductivity, $\mathrm{DO}=$ Dissolved Oxygen, $\mathrm{TDS}=$ Total Dissolved Solid, Alk $=$ Alkalinity, $\mathrm{TH}=$ Total Hardness, Turb. $=$ Turbidity

\subsection{Factor analysis model}

Factor analysis is a statistical method used to identify "factors" that explain a variety of results on different tests. Through the factor analysis, assumptions are made that underlying causal models exist in results on different tests. This assumption is based on the fact that parameters with loadings whose absolute value is more than 0.6 are considered significant (Selvakumar et al. 2014). In this study, the spatial distributions 
of different chemical analytes were related to different possible sources (factors), which have different chemical signatures. The results showed that the analytes in each of the study area was affected by four factors. However, two factors ( 1 and 2 for Ezza North, 1 and 3 for Ezza South) have strong positive loading on some of the parameter and were considered significant (values are $\geq 0.6$ ).

Factor 1 had strong positive loadings on $\mathrm{pH}$, temperature, dissolved oxygen, total dissolved solid, turbidity, $\mathrm{PO}_{4}{ }^{3-}, \mathrm{Cl}^{-}, \mathrm{NO}_{3}{ }^{-}, \mathrm{SO}_{4}{ }^{2-}$, and $\mathrm{As}(\mathrm{V})$ in the two study areas. The positive loadings suggested that results could have been influenced by natural causes, possibly from the soil's geochemistry. Factor 2 (for Ezza North) and factor 3 (for Ezza South) had strong positive loadings on electrical conductivity, alkalinity and total hardness. The positive loadings suggested that results could have resulted from anthropogenic causes, possibly from the agricultural, commercial and mining activities. Factors 2 and 4 (for Ezza North) and factors 2 and 4 (for Ezza South) had little loadings on the analytes.

Table 6. Factor Analysis numbers (Varimax rotation) of various analytes in Ezza South

\begin{tabular}{ccccc}
\hline Analyte & Factor 1 & Factor 2 & Factor 3 & Factor 4 \\
\hline pH & $\mathbf{0 . 8 3 6 7 6}$ & -0.30859 & 0.45168 & 0.0155 \\
Temp. & $\mathbf{0 . 8 0 9 2 9}$ & -0.35955 & 0.46144 & 0.033085 \\
EC. & 0.49623 & -0.3002 & $\mathbf{0 . 7 9 9 6 8}$ & 0.15532 \\
DO & $\mathbf{0 . 7 9 8 2 8}$ & -0.35852 & 0.48347 & -0.01016 \\
TDS & $\mathbf{0 . 7 3 3 5 2}$ & -0.21394 & 0.63886 & 0.087677 \\
Alk. & 0.35661 & -0.87093 & 0.33641 & 0.0032852 \\
TH & 0.39978 & -0.40232 & 0.79729 & -0.20651 \\
Turb. $_{\text {PO }^{3-}}$ & $\mathbf{0 . 7 7 6 9}$ & -0.56298 & 0.26666 & -0.00071273 \\
$\mathbf{C l}^{-}$ & $\mathbf{0 . 8 0 9 4 3}$ & -0.4007 & 0.42153 & 0.0016363 \\
$\mathbf{N O}_{3}^{-}$ & $\mathbf{0 . 7 8 1 1 4}$ & -0.32851 & 0.52742 & 0.019845 \\
$\mathbf{S O}_{4}{ }^{--}$ & $\mathbf{0 . 7 7 1 4 6}$ & -0.2989 & 0.55841 & 0.05542 \\
$\mathbf{A s}(\mathbf{V})$ & $\mathbf{0 . 7 9 8 3 1}$ & -0.33064 & 0.48739 & -0.11677 \\
\hline
\end{tabular}

Values of factors that had strong positive loading on the analyte are in bold $(\geq 0.6)$.

Temp. $=$ Temperature, EC. $=$ Electrical Conductivity, $\mathrm{DO}=$ Dissolved Oxygen, $\mathrm{TDS}=$ Total Dissolved Solid, Alk = Alkalinity, $\mathrm{TH}=$ Total Hardness, Turb. $=$ Turbidity

\subsection{Comparison with other Reports of Groundwater Studies}

A comparison of the observed mean concentrations of chemical contaminants in this study with those reported in previous studies conducted in an area of Ghana (Tarkwa area) shows that they were of the same magnitude with their turbidity $\left(10-34\right.$ NTU), TDS $\left(40-654 \mathrm{mg}^{-1}\right)$ and conductivity $(68.9-105$ $\mu \mathrm{S} \mathrm{cm}^{-1}$ ) (Armah et al. 2010). However, for the As, their mean values ranged from $0.000-0.004 \mathrm{mg} \mathrm{l}^{-1}$. With regards to $\mathrm{As}(\mathrm{V})$, mean values of $0.0036-0.0252 \mathrm{mg} \mathrm{l}^{-1}$ were found in Agyapesuwa, Agona and Bumafua (Ghana) (Nyamah and Torgbor, 1986). As concentrations greater than $10 \mathrm{\mu g}^{l^{-1}}$ was reportedly found in privately owned drinking wells in New England (Ayotte et al. 2003) and a review published in 2012 of 14 Latin American countries showed As concentrations greater than $10 \mathrm{\mu g} \mathrm{l}^{-1}$ for a century (Bundschuh et al. 2012).

\section{Conclusion}

This study has shown that the quality of the groundwater samples in rural areas of Ebonyi State, Southeastern Nigeria are influenced mainly by soil's geochemistry and slightly by commercial or agricultural activities. There was no evidence that the proximity of sampled points to the quarry mine-pits in Ezza North influenced the levels of the chemical contaminants analysed in that area. The results of the factor analysis suggested that most of the variations are explained by the set of natural causes (soil's geochemistry) and anthropogenic causes. Adequate monitoring of $\mathrm{As}(\mathrm{V})$, and other potential toxic contaminants in groundwater samples is advocated as this will help local authorities set new guidelines for various contaminants that affect water quality. 


\section{Acknowledgement}

The authors are grateful to Dr. Omaka for his support in providing some of the reagents and materials used in this work. The contributions of Messrs. Igwe, Oroke and Ofoezue, who assisted in laboratory works, are grateful acknowledged. Thanks to Nwali and Ngele who assisted with the sampling.

\section{References}

American Public Health Association (APHA), American Water Works Association (AWWA) and Water Environment Federation (WEF). (2012), Standards methods for the examination of water and wastewater (22nd ed.). New York: American Public Health Association (APHA), American Water Works Association (AWWA) \& Water Environment Federation (WEF).

Armah F.A., Obiri S., Yawson D.O., Pappoe A.N. and Bismark A. (2010), Mining and Heavy Metal Pollution: Assessment of Aquatic Environments in Tarkwa (Ghana) using Multivariate Statistical Analysis, Journal of Environmental Statistics, 1(4), 1-13.

Ayotte J.D., Montgomery D.L., Flanagan S.M. and Robinson K.W. (2003), Arsenic in Groundwater in Eastern New England: Occurrence, Controls, and Human Health Implications, Environ. Sci. Technol., 37, 2075-2083.

Bednar A.J., Garbarinoa J.R., Burkhardta M.R., Ranville J.F. and Wildeman T.R. (2004), Field and Laboratory Arsenic Speciation Methods and their Application to Natural-water Analysis, Water Research, 38, 355-364.

Bundschuh J., Litter M.I., Parvez F., Román-Ross G., Nicolli H.B., Jean J.-S. and Toujaguez R. (2012), One Century of Arsenic Exposure in Latin America: A Review of History and Occurrence from 14 Countries, Science of the Total Environment, 429, 2-35.

Duruibe J.O., Ogwuegbu M.O. and Egwurugwu J.N. (2007), Pollution Profiles of Non-metallic Inorganic and Organic Pollutants of Drinking and Potable Waters due to Mining Activities in Ishiagu (Ebonyi State) of Nigeria, International Journal of Physical Sciences, 2(8), 202-206.

Ezeh H.N. and Anike O.L. (2009), The Preliminary Assessment of the Pollution Status of Streams and Artificial Lakes Created by Mining in the Mining District of Enyigba, Southeastern Nigeria, and their Consequences, Global Journal of Environmental Sciences, 8(1), 41-48.

Gómez M.J., Herrera S., Solé D., García-Calvo E. and Fernández-Alba A.R. (2012), Spatio-temporal Evaluation of Organic Contaminants and their Transformation Products along a River Basin Affected by Urban, Agricultural and Industrial Pollution, Science of the Total Environment, 420, 134-145.

Halliwell D.J., McKelvie I.D., Hart B. and Dunhill R.H. (1996), Separation and Detection of Condensed Phosphates in Waste Waters by Ion Chromatography Coupled with Flow Injection, Analyst, 121, 1089-1093.

Heal K.V. (2001). Manganese and Land-Use in Upland Catechments in Scotland, The Science of the Total Environment, 265, 169-179.

Jenkins D. and Medsken L. (1964), A Brucine Method for the Determination of Nitrate in Ocean, Estuarine, and Fresh Waters, Analytical Chemistry, 36, 610.

MacDonald A.M., Cobbing J. and Davies J. (2005), Developing Groundwater for Rural Water Supply in Nigeria: a Report of the May 2005 Training Course and Summary of Groundwater Issues in the Eight Focus States. British Geological Survey Commissioned Report CR/05/219N.

Mendham J., Denney R.C., Barnes J.D. and Thomas M. (2004), Vogel's Textbook of Quantitative Chemical Analysis (6th ed.). Delhi, India: Pearson Education Ltd.

Monteiro M., Ferreira F. and de Oliveira N.A. (2003), Simplified Version of Sodium Salicylate Method for Analysis of Nitrate in Drinking Waters. Analytica Chimica Acta, 477, 125-129.

Nnabo P.N., Orazulke D.M. and Offor O.C. (2011), The Preliminary Assessment of the Level of Heavy Elements Contaminations in Stream Bed Sediments of Enyigba and Environs, South Eastern Nigeria, Journal of Basic Physical Research, 2(2), 43-52.

Nyamah D. and Torgbor J.O. (1986), Colorimetic Method for the Determination of Arsenic in Potable Water, Water Resources, 20(11), 1341-1344.

Omaka O.N. (2007), Phosphorus in the Environment, Effects of Eutrophication, Cycle, Fractionation, Determination and Procedures for Sampling and Storage - A Review, Journal of Applied and Natural Sciences, 1(1), 27-36. 
Omaka O.N., Nwabue F.I., Itumoh E.J., Oroke E.C. and Igwe D.O. (2014), Physicochemical Parameters and nutrients Variations of Streams and Rivers in Abakaliki, Ebonyi State, Nigeria, Global NEST Journal, 16(1), 114-123.

Pistón M., Silva J., Pérez-Zambra R., Dol I. and Knochen M. (2012), Automated Method for the Determination of Total Arsenic and Selenium in Natural and Drinking Water by HG-AAS, Environmental Geochemistry and Health, 34(2), 273-278.

Prior H. and Jones P. (2002), Regulation of Surface Water Quality in a Cretaceous Chalk Catchment, UK: an Assessment of the Relative Importance of Instream and Wetland Processes, The Science of the Total Environment, 282-283, 157-174.

Reyment R.A. (1965), Aspects of Geology of Nigeria. Ibadan: Ibadan University Press.

Selvakumar S., Ramkumar K., Chandrasekar N., Magesh, N. S., and Kaliraj, S. (2014). Groundwater Quality and its Suitability for Drinking and Irrigational Use in the Southern Tiruchirappalli District, Tamil Nadu, India. Appl. Water Sci. doi:10.1007/s13201-014-0256-9

Standard Organisation of Nigeria (SON). (2007). Nigerian Standard for Drinking Water Quality (Nigerian Industrial Standard NIS 554:2007). Abuja: Standard Organisation of Nigeria (SON).

Steiner-Asiedu M., Anderson A.K., Vuvor F. and Asiedu D. K. (2010), Exposure to Arsenic in Drinking Water-Public Health Debates and Concerns, Research Journal of Environmental and Earth Sciences, 2(1), 1-5.

Sundaram B., Feitz A., Caritat P.D., Plazinska A., Brodie R., Coram J. and Ransley T. (2009), Groundwater Sampling and Analysis - A Field Guide. Canberra, Australia: Geoscience Australia.

Villa-Lojo M.C., Alonso-Rodriguez E., Lopez-Mahia P., Muniategui-Lorenzo S. and Prada-Rodriguez D. (2002), Coupled High Performance Liquid Chromatography-Microwave Digestion-Hydride Generation-Atomic Absorption Spectrometry for Inorganic and Organic Arsenic Speciation in Fish Tissue, Talanta, 57, 741-750.

Withers P. and Lord E. (2002), Agricultural Nutrients Inputs to Rivers and Groundwaters in the UK: Policy, Environmental Management and Research Needs, The Science of the Total Environment, 282-283, 9-24.

World Health Organisation (WHO) (2011), Guidelines for Drinking-water Quality. Geneva: World Health Organisation (WHO).

Zanin L., Robertson W., Ptacek C. and Schiff S. (1998), Phosphorus Characterization in Sediments Impacted by Septic Effluent at Four Sites in Central Canada, Journal of Contaminant Hydrology, 33, 405-429.

Zatar N.A., Abu-Eid M. and Eid A.F. (1999), Spectrophotometric Determination of Nitrite and Nitrate Using Phosphomolybdenum Blue Complex, Talanta, 50, 819-826. 